\title{
Alleviation of Atopic Dermatitis through Probiotic and Mixed-probiotic Treatments in an Atopic Dermatitis Model
}

\author{
Jae-Gu Seo, Myung-Jun Chung, and Hyun-Gi Lee* \\ R\&D Center, Cellbiotech, Co. Ltd., Gimpo 415-871, Korea
}

\begin{abstract}
The use of lactic-acid bacteria (LAB) is effective for preventing and curing immune disorders by activating the immune system in the digestive tract and the consequent immune response in the blood. In this study, LAB and mixed LABs were used in an atopic dermatitis (AD) mouse model. Alleviation of AD was observed based on the change in cytokine level and immunohistochemical staining. An ex vivo test showed that immunoglobulin-E and interleukin (IL)-4 levels were significantly lower in all groups treated with LAB than in the group treated with only 1-chloro-2,4-dinitrobenzene. Results of an in vivo test based on the ex vivo results showed that the scratch score decreased in all groups treated with the LAB and particularly decreased in the group treated with mixed LABs. Additionally, the T helper (Th) 1 cytokines interferon-gamma and IL-12p40 were upregulated by the LAB and mixed-LABs, whereas levels of the Th2 cytokine IL-4 were downregulated in a mouse model of AD-like skin lesions. Furthermore, hematoxylin \& eosin and immunohistochemical staining of the dorsal area of the mice in each group showed that AD improved in the LAB-treated groups. These results suggest that LAB and mixed LABs inhibit the development of AD in NC/Nga mice by suppressing the Th2 cell response and increasing the Th1 cell response. Our results indicate that mixed LABs are better than LAB for treating AD-like skin lesions.
\end{abstract}

Key words: lactic acid bacteria, atopic dermatitis, 1-chloro-2,4-dinitrobenzene, cytokines

\section{Introduction}

Atopic dermatitis (AD) is a chronic or recurrent inflammatory skin disorder (Leung et al., 2003). AD affects mainly infants and young children, and its prevalence is increasing rapidly in the world (Mancini et al., 2008). Furthermore, AD is not only a skin disorder but is also a signal of allergic march, such as allergic asthma or rhinitis (Ker et al., 2009). The accurate pathophysiology of $\mathrm{AD}$, however, has not yet been defined. Until now, it is known to be a multifactorial disease involved with genetic susceptibility, an immune response to increased antigens by the impaired skin and the gut barrier function, and the product of a certain lifestyle (e.g., dietary habits) and of the environment (Wakabayashi et al., 2008). It is not easy to cure $\mathrm{AD}$, and it is necessary to manage some of its modifiable risk factors and to modulate the immune reactions to it.

Also, various immunologic disturbances have been reported in atopic patients. Their related skin lesions showed

*Corresponding author: Hyun-Gi Lee, Cellbiotech, Gimpo 415872, Korea. Tel: 82-31-987-6205, Fax: 82-31-987-8102, Email: hglee@cellbiotech.com excessive production of IL-4, IL-5, IL-9, IL-10, and IL13 by the Th2-cell-mediated immune response (Kay et al., 1991; Ohmen et al., 1995; Tazawa et al., 2004). Moreover, $\mathrm{AD}$ is related to elevated serum $\operatorname{IgE}$ levels and to the decreased production of IL-12 and IFN- $\gamma$ by the Th1 immune reaction (Lester et al., 1995; Rosenfeldt et al., 2003).

Lactic acid bacteria (LAB) are emerging as useful supplements for $\mathrm{AD}$. It is reported that some LAB strains, such as Lctobacillus rhamnosus, Lactobacillus reuteri, Bifidobacterium bifidum, Bifidobacterium lactis, and Lactobaccilus acidophilus, are effective in the treatment of AD in children (Kalliomaki et al., 2001; Rousset et al., 1991). LABs are a primary prevention in infants at high risk of $\mathrm{AD}$ (Kim et al., 2010). However, AD is not yet consistent (Brouwer et al., 2006; Folster-Holst et al., 2006; Taylor et al., 2007). It was also reported that this effect may depend on the kind of LAB strain used (Wakabayashi et al., 2008).

$\mathrm{NC} / \mathrm{Nga}$ mice originated from Japanese fancy mice at Nagoya University (Nagoya, Japan) in 1957. They develop AD-like skin lesions and IgE hyperproduction under conventional conditions with itching, erythema, and hemorrhage, followed by edematous superficial erosion, deep 
excoriation, scaling, dryness of the skin, and retarded growth (Vestergaard et al., 2000; Matsuda et al., 1997). These pathophysiologic observations in $\mathrm{AD}$ of $\mathrm{NC} / \mathrm{Nga}$ mice highly resemble those in human $\mathrm{AD}$, so this strain of mouse has been considered a useful animal model to study pathologic mechanisms of human AD (Suto et al., 1999).

In the present study, the immune responses and cytokine expressions of several LAB strains (Lactobacillus casei, Lactobacillus rhamnosus, Lactobacillus plantarum, and Bifidobacterium lactis), respectively, and a mixture of 1-chloro-2,4-dinitrobenzene (DNCB)-treated whole blood cells were investigated through an in-vitro test, and the beneficial effects of such LAB strains were examined using $\mathrm{NC} / \mathrm{Nga}$ mice on which $\mathrm{DNCB}$ was repeatedly applied cutaneously, which are suitable models for AD. Furthermore, the action mechanism of LAB in the treatment of $\mathrm{AD}$ was elucidated.

\section{Materials and Methods}

\section{LAB samples and reagents}

The Lactobacillus casei (LC), Lactobacillus rhamnosus (LR), Lactobacillus plantarum (LP), and Bifidobacterium lactis (BL) that were used $\left(10^{8} \mathrm{CFU} /\right.$ head) and orally administered once daily in this study were cultured from the CELLBIOTECH Co. culture collection (Korea). The $\mathrm{LAB}$ was isolated with a separator. The 1-chloro-2,4-dinitrobenzene (DNCB) was purchased from Sigma (USA) and was used after recrystallization with acetone.

\section{Ex-vivo test}

The whole blood cells obtained from normal NC/Nga mice were mixed at a ratio of 1:5 in IEME media $(2 \mathrm{nM}$ glutamax, 10\% FBS, $50 \mu \mathrm{mol}$ betamercaptoethanol, 0.1\% penicillin-streptomycin complex, $\mathrm{pH}$ 7.4, Gibco). Fifty microliters of whole blood cells were placed in the prepared $150-\mu \mathrm{L}$ IMEM media $(10 \%$ FBS, 0.1 penicillinstreptomycin complex, $\mathrm{pH}$ 7.4) in each well of a 96-well plate, and were then cultured for $24 \mathrm{~h}$ in a $5 \% \mathrm{CO}_{2}$ incubator. The whole blood cells were dropped $(50 \mu \mathrm{L}$ in each well) in an atopic environment created by adding $3 \mu \mathrm{g} /$ $\mathrm{mL}$ DNCB in a solution of acetone and ethanol mixed at a ratio of 1:4, after which the cells were incubated for 12 h. One $\mu \mathrm{g} / \mathrm{mL}-\mathrm{LAB}$-sample-treated whole blood cells were also incubated for $12 \mathrm{~h}$, and supernatants were used for measurement after centrifuging at $1,000 \mathrm{rpm}$ at $4^{\circ} \mathrm{C}$ for $10 \mathrm{~min}$. After the supernatant was obtained in the whole-blood-cell culture test, the levels of IgE (Mouse
IgE ELISA Kit, BD Bioscience) and IL-4 (Mouse IL-4 Immunoassay ELISA Kit, R\&D Systems) were measured.

\section{Animals and induction of AD-like skin lesions}

Eight-week-old male NC/Nga mice were purchased from Central LAB Animal Inc. (Korea) and were acclimatized for one week, with free access to water and a basic diet consisting of AIN-76A. They were housed in an air-conditioned room whose temperature was maintained at $24 \pm 1^{\circ} \mathrm{C}$ and with $55 \pm 10 \%$ humidity and lighting (lights on from 07:00 to 19:00). All the animal procedures and experiments that were conducted were in accordance with Guidelines for Animal Experiments (CBTA-005). The mice were anesthetized with ether, and their back hair was shaved with a clipper and a shaver. AD-like skin lesions were induced by sensitization to and repeated challenge with DNCB. Briefly, to induce $\mathrm{AD}$, the mice were treated with a $0.5 \%$ DNCB solution six times in two weeks, after which they were treated with a $1 \%$ DNCB solution four times in two weeks. The DNCB solution was manufactured by adding DNCB to acetone:olive oil at a ratio of $3: 1$. During the experiment, the body weight changes were measured two times per week for six wk. After three mice were randomly chosen from a group and were transferred to a new cage, the numbers of times that they scratched were counted for $10 \mathrm{~min}$ and were then averaged.

\section{Collection of tissue samples}

The mice were etherized after $12 \mathrm{~h}$ starvation, and their colons and lymph nodes were extracted. Each colon was cut into three pieces, and the piece that was farthest from the cecum was sliced for the observation of the mucosa. The lymph node and the colon tissues were washed three or four times with $\mathrm{PBS}$ at $0^{\circ} \mathrm{C}$, and were then stored at $-70^{\circ} \mathrm{C}$ until use. The tissue samples for $\mathrm{H} \& \mathrm{E}$ staining were fixed in a $10 \%$ formalin solution and were then stored at $4^{\circ} \mathrm{C}$.

\section{Biochemical serum analysis}

Blood was collected from the heart under ether anesthesia, and plasma was immediately prepared via centrifugation and then stored at $-20^{\circ} \mathrm{C}$ until use. The plasma levels of IgE, IL-4 (Mouse IL-5 Immunoassay ELISA Kit, R\&D Systems), IL-12 (Mouse IL-12 p70 Immunoassay ELISA Kit), and IFN-gamma (Mouse IFN Immunoassay ELISA Kit) were measured ten times via dilution, and the plasma levels of immunoglobulin $\mathrm{G}$ (IgG) were measured using a 
Luminex® 100TM instrument set (Komabiotech, Seoul, South Korea).

\section{Microscopic observation}

For the preparation of the skin samples for pathological examination, the skin tissue with $\mathrm{AD}$ was cut off, fixed in $10 \%$ formalin for $24 \mathrm{~h}$, and washed with water. The tissue was dehydrated in alcohol (for $1 \mathrm{~h}$ each in 70, 80, 90, and $100 \%$ ) and xylene (3 steps, $1 \mathrm{~h}$ for each step), and was embedded into paraffin. The paraffin block was sliced at $7 \mu \mathrm{m}$ thickness, stained with hematoxylin-eosin (H\&E), and observed with a microscope. The tissue was also immunohistochemically stained with anti-IL-4 antibody (1: 50 dilution; Santacruz Biotechnology, Inc., CA, USA) and diaminobenzidine (DAB, 2-min colorization), and was examined under a microscope.

\section{Statistical analysis}

The data were processed with Graphpad PrismTM 5.0, and the statistical parameters, mean value, and standard deviation in a group were calculated and compared with those from other groups. The significance was determined via ANOVA $(p<0.05)$.

\section{Results}

\section{Ex-vivo assay of the change in the cytokine level}

From the NC/Nga mice with AD, whole blood was collected and cultured. The cultured whole blood was treated with either $\mathrm{LAB}$ or mixed $\mathrm{LAB}$, and the changes in the IgE and IL-4 levels in the culture were observed. The IgE level significantly decreased in all the groups treated with $\mathrm{LAB}$ or mixed $\mathrm{LAB}$ compared with the groups with $\mathrm{AD}$, and in particular, in the LAB-treated groups, it decreased

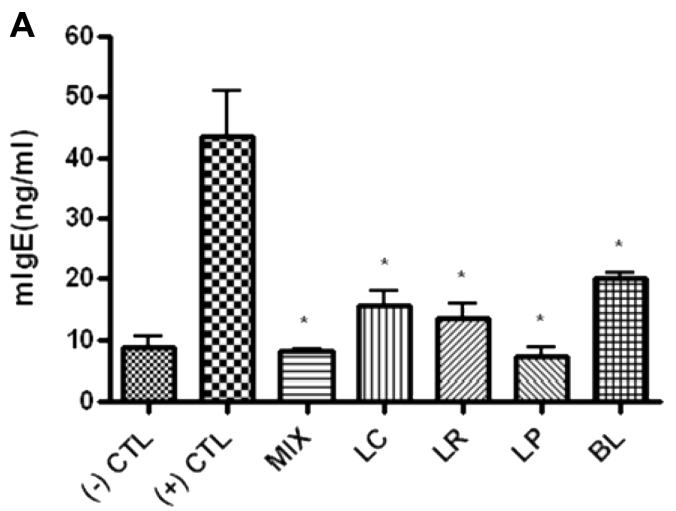

to a level close to the normal level (Fig. 1A). As such, although the level of IL-4 that induces the synthesis of IgE was significantly lower in the LAB-treated groups than in LAB-untreated groups, it was not considerably different between the groups treated with LAB and those treated with mixed LAB (Fig. 1B).

\section{Improvement of the scratch score through the oral administration of LAB}

Either LAB or mixed LAB was orally administered to the NC/Nga mice with DNCB-induced AD for six weeks. Then gross examination for dermatitis was performed, and the scratch scores were measured. When LAB was administered during the experiment period, no decrease in body weight due to $\mathrm{LAB}$ or to the stress resulting from the oral administration of $\mathrm{LAB}$ was observed.

The scratch score, an indicator of $\mathrm{AD}$, was constantly high in the positive control whereas it significantly decreased in all the groups treated with LAB. Among the LABtreated groups, that to which mixed LAB was administered showed the largest decrease in scratching (Fig. 2A). In addition, the gross examination of the inflammation in each group after the completion of the experiment showed that the level of inflammation in all the LAB-treated groups decreased to a level close to that of the normal group (Fig. 2B).

\section{Changes in the serum cytokine levels due to the oral administration of LAB}

Both the scratch scores and the gross examination results showed that the serum cytokine levels in the $\mathrm{NC} /$ Nga mice changed based on the alleviation of AD. The levels of both IgE and IL-4 decreased more in the LABtreated groups than in the LAB-untreated groups, and par-

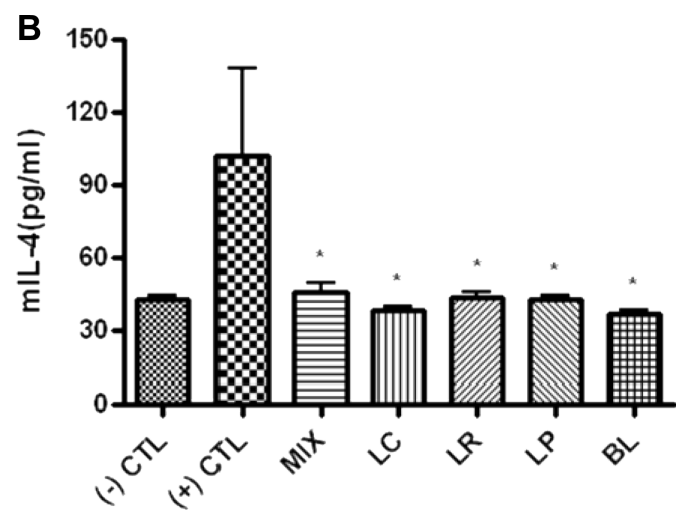

Fig. 1. Effects of various LAB strains on IgE (a) and IL-4 (b) secretion from the DNCB-treated whole blood cells in vitro. Whole blood cells were prepared from NC/Nga mice. IgE and IL-4 levels were measured by ELISA. The results are expressed as means $\pm \mathrm{SD}(\mathrm{n}=5) .{ }^{*} p<0.05$ vs. $(+)$ control. LAB, lactic acid bacteria; LC, Lactobacillus casei; LR, Lactobacillus rhamnosus; LP, Lactobacillus plantarum; BL, Bifidobacterium lactis 


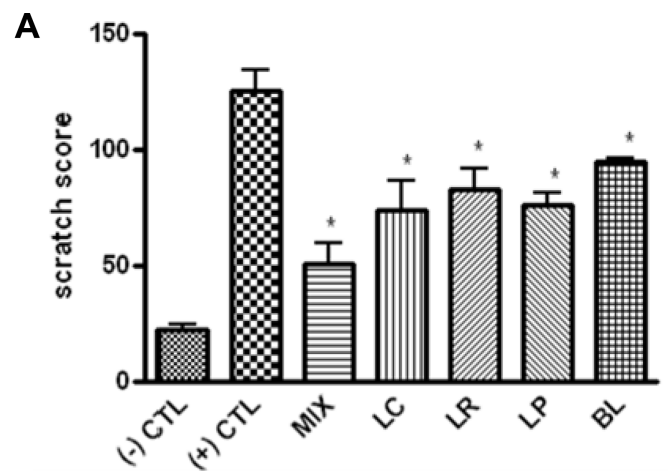

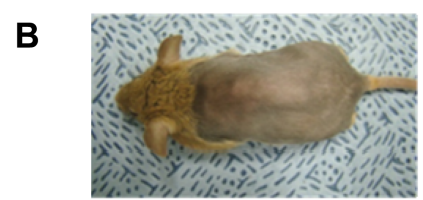

a. $(-) C \pi$

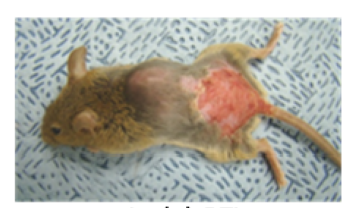

b. (+)CTL

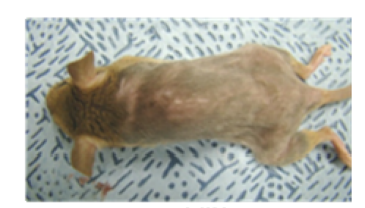

c. MIX

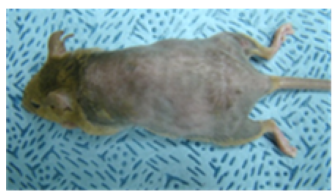

d. LC

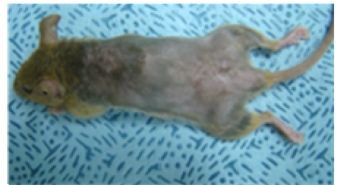

e. LR

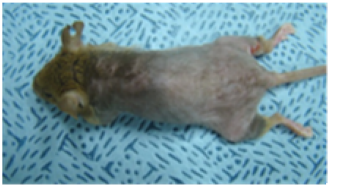

f. LP

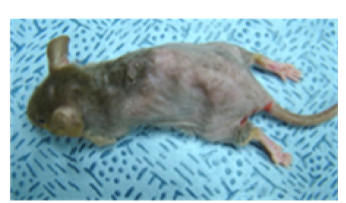

g. BL

Fig. 2. Photographs of skin features and scratch score in NC/Nga mice. A: Changes of the scratch score on DNCB-induced AD-like skin lesions in NC/Nga mice. The mice were fed respectively the LAB mixture, LC, LR, LP and BL for 6 wk. Scratch score on facial and back skin was measured for 10 min at 1 -wk intervals. The results are expressed as means $\pm \mathrm{SD}(\mathrm{n}=3) .{ }^{*} p<0.05$ vs. $(+)$ control. LAB, lactic acid bacteria; LC, Lactobacillus casei; LR, Lactobacillus rhamnosus; LP, Lactobacillus plantarum; BL, Bifidobacterium lactis. B: Atopic dermatitis-NC/Nga mouse induced by $(1 \rightarrow 0.5 \%)$ DNCB solution treated with indicated LAB (Mixture, LC, LR, LP, BL) sample for 6 weeks Normal mice without DNCB-induced AD-like skin lesions (a), control mice with DNCB-induced AD-like skin lesions (b) and experimental mice of LAB and LAB mixture administration with DNCB-induced AD-like skin lesions $(\mathrm{d}-\mathrm{g})$
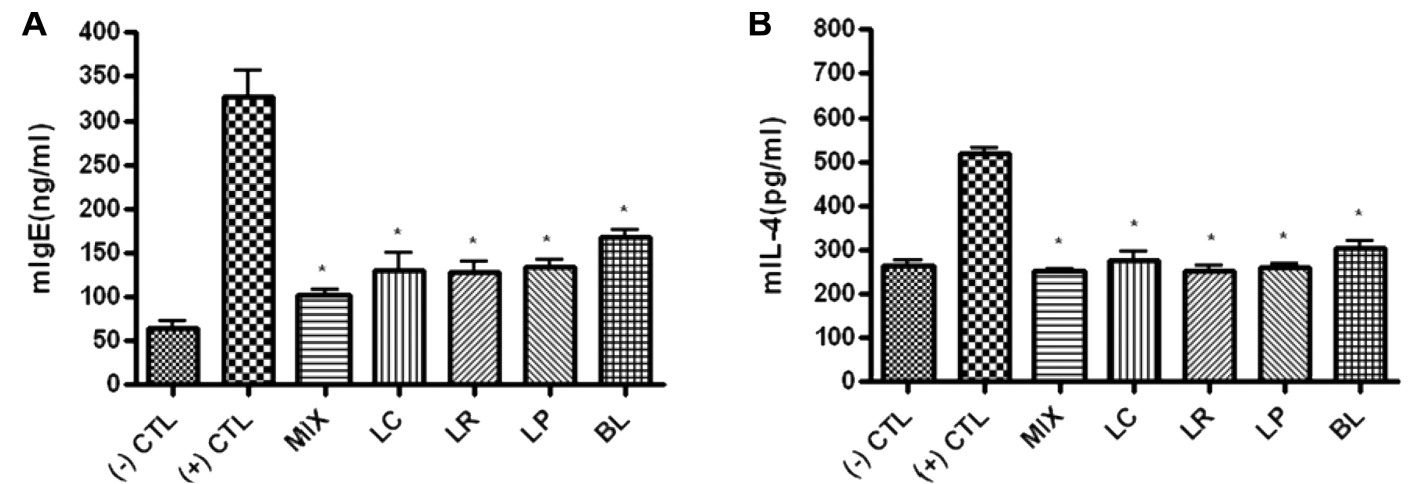

Fig. 3. Serum levels of immunoglobulin (Ig) $\mathbf{E}$ and Th2-related cytokines (IL-4) in the experimental groups. $\mathrm{mIgE}$ (A) and $\mathrm{mIL}-4$ (B) were measured by using ELISA kit. The results are expressed as means $\pm \mathrm{SD}(\mathrm{n}=5) .{ }^{*} p<0.05$ vs. $(+)$ control. LAB, lactic acid bacteria; LC, Lactobacillus casei; LR, Lactobacillus rhamnosus; LP, Lactobacillus plantarum; BL, Bifidobacterium lactis.

ticularly decreased more in the mixed-LAB-treated group than in the other groups (Fig. 3).

The measurement of the levels of IL-12 and IFN-gamma, both of which are Th1-related cytokines that inhibit the expression of IL-4, a type of cytokine related with Th2, revealed that the IL-12 level was lower in the positive control than in the negative control. In contrast, the IL-12 level significantly increased in all the LAB-treated groups, and was similar to that of the groups in which $\mathrm{AD}$ was not induced.

Similar to IL-12, IFN-gamma also increased. Although the significantly increased IL-12 level in the LAB-treated groups became close to that of the negative control, the IFN-gamma level increased in all the LAB-treated groups, 

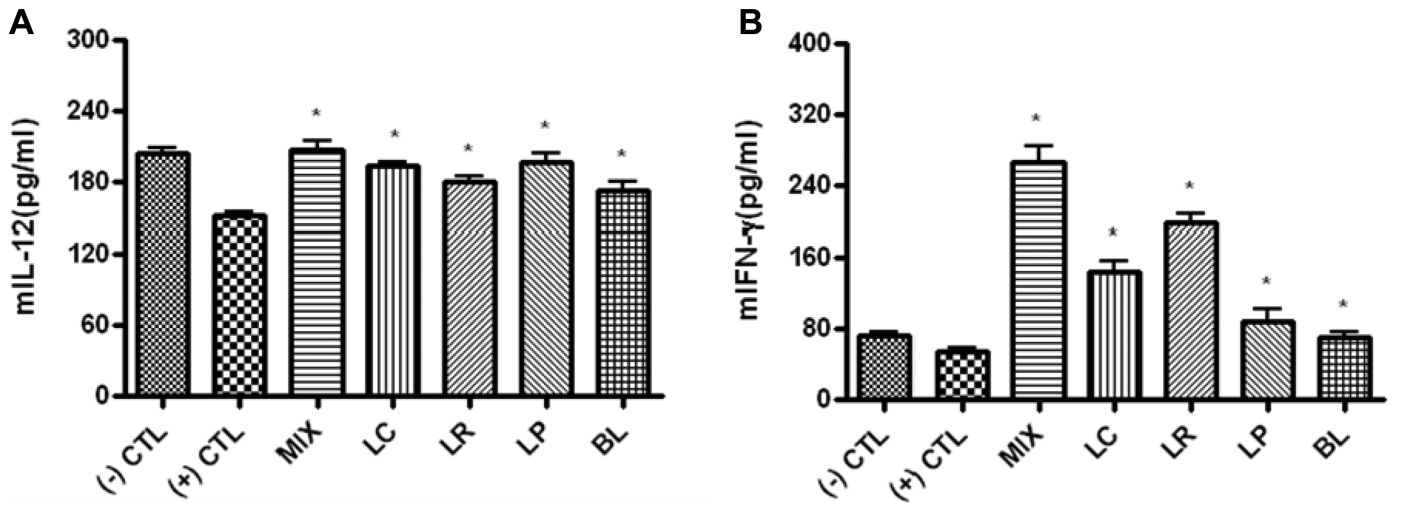

Fig. 4. Effects of various LAB strain administrations on serum levels of Th1-related cytokines in NC/Nga mice. $\mathrm{mIL}-12$ (A) and mIFN-gamma (B) were measured by ELISA. The results are expressed as means $\pm \mathrm{SD}(\mathrm{n}=6) .{ }^{*} \mathrm{p}<0.05$ vs. $(+)$ control. LAB, lactic acid bacteria; LC, Lactobacillus casei; LR, Lactobacillus rhamnosus; LP, Lactobacillus plantarum; BL, Bifidobacterium lactis

$(-)$ CTL $\quad(+)$ CTL

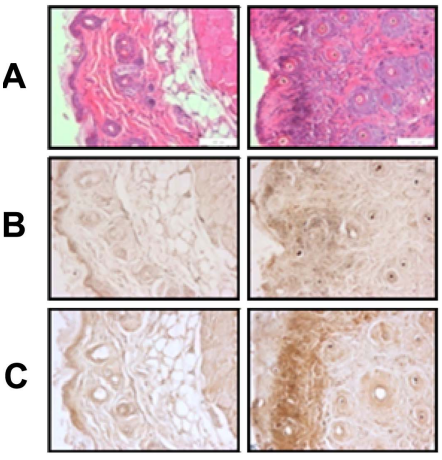

MIX

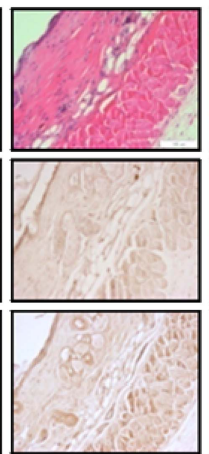

LC'

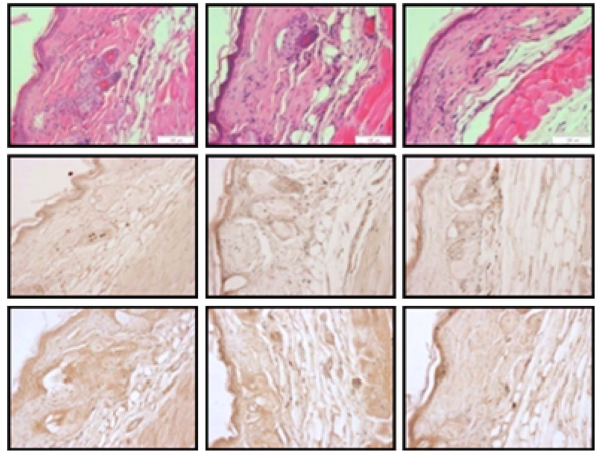

BL

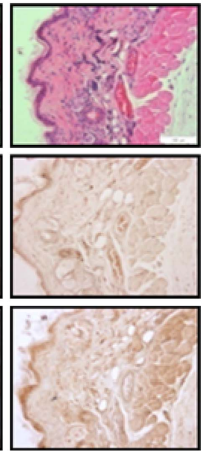

Fig. 5. Histopathologic features of back skin induced by DNCB and effects of repeated administration of LAB samples. A: Magnification of hematoxilin \& eosin (H\&E) staining were 200. Histopathologic features of expression of IL-4 (A) and IL-5 (B) on DNCB-induced AD-like skin lesion. (-)CTL: Normal mice without DNCB-induced AD-like skin lesions, $(+)$ CTL: control mice with DNCB-induced AD-like skin lesions, experimental mice (Mixture, LC, LR, LP, BL) of LAB mixture administration with DNCB-induced AD-like skin lesions. LAB, lactic acid bacteria; LC, Lactobacillus casei; LR, Lactobacillus rhamnosus; LP, Lactobacillus plantarum; BL, Bifidobacterium lactis IHC stain, 200

particularly in the group treated with mixed LAB (Fig. 4).

\section{Histopathology after the oral administration of LAB}

The H\&E staining of the dermal tissues that were removed from the NCNC/Nga mice in each group showed that the epidermises and dermises were thicker, and more mast cells and eosinophils were found in the positive control, in which AD was induced, than in the negative control (Fig. 5A). After IHC staining for IL-4 and IL-5 in the dermal tissues, IL-5 was observed in the subcutaneous tissues of the positive control. This indicated that the ADinducing agents activated the immune system, particularly the Th2 cells, thereby increasing the production of $\mathrm{IgE}$ in the B cells, and inducing the activation of the mast cells and basophils in this region, consequently causing an allergic reaction (Fig. 5B,C). In contrast, the H\&E staining of the dermal tissues of the mice in which $\mathrm{AD}$ was induced but that were treated with LAB showed thickened epidermises and dermises, and the increased number of immune cells returned to the normal level.

\section{Discussion}

The beneficial effect of $\mathrm{LAB}$ for $\mathrm{AD}$ has been well reported in many studies, although there have been few studies on the effects of particular LAB (e.g., L. casei, $L$. rhamnosus, L. plantarum, and B. lactis). In this study, the treatment effects of LC, LR, LP, and BL, all of which are $\mathrm{LAB}$, in the NC/Nga mice with DNCB-induced AD were examined, and the degrees of alleviation of $A D$ through the administration of LAB and mixed LAB were compared.

First, the alleviation of $\mathrm{AD}$ through the administration 
of mixed LAB was indirectly examined using the whole blood collected from the mouse models in which AD was induced. The IgE and IL-4 levels were significantly lower in the LAB-treated groups than in the LAB-untreated groups. The IgE levels were slightly lower in the mixedLAB-treated groups than in the group treated with a single LAB strain. As for the IL-4 level, it was lower in all the LAB-treated groups than in the control.

In addition, there was a slight difference between the single LAB strain and mixed LAB, although such difference was not significant. The previous studies reported that the IgE produced from the B cells degranulated the mast cells and activated the eosinophils (Gunther et al., 2005; Hiroi et al., 1998; Homey et al., 2006; van der Kleij et al., 2004). Thus, based on the fact that the single LAB strain and the mixed LAB inhibited IgE, the possibility of alleviating $\mathrm{AD}$ through the administration of LAB was suggested.

Previous studies reported that in an NC/Nga mouse model, LAB reduced the scratch score and the AD symptoms. The scratch score is considered an important indicator of the alleviation of $\mathrm{AD}$. It is a critical element in reducing the symptoms of $\mathrm{AD}$ as well as in preventing secondary infection. Although the results of this experiment regarding the effect of the administration of a single LAB strain and mixed-LAB on the scratch score are not sufficient to meet the requirements for the alleviation of $\mathrm{AD}$, they are considered valid for the alleviation of primary $\mathrm{AD}$. The change in the cytokine level in $\mathrm{AD}$ is known to be triggered by the immune system based on the activation of $\mathrm{Th} 2$, in which the differentiation of the undifferentiated $\mathrm{T}$ helper (Th) cell into $\mathrm{Th} 2$ is overly facilitated. In this process, the Th2 cell produces interleukin-4 (IL-4), IL-5, Il-13, IL-9, and IL-10 (Ferrick et al., 1995; Pivarcsi et al., 2004; Viljanen et al., 2005). Among these, IL-4 and Il-13 promote the synthesis of immunoglobulin $\mathrm{E}(\mathrm{IgE})$ and $\operatorname{IgG} 1$. In humans, they are known to promote the synthesis of IgE and IgG4 (Aversa et al., 1993; Matsuda et al., 1997). In this study, the examination of the pattern of changes in the cytokines related with the serum Th2 of the mice after the administration of a single LAB strain and mixed LAB showed that $\operatorname{IgE}$ and Il-4 decreased in the LAB-untreated groups. In particular, IgE showed a bigger decrease trend in the mixed-LABtreated groups than in the groups to which a single LAB strain was administered. In addition, the $\operatorname{IgE}$ levels of the positive control increased fourfold those of the negative control, whereas the IgE levels of the LAB-treated groups significantly decreased threefold those of the positive control, with the largest decrease found in the mixedLAB-treated groups. Moreover, the IL-4 level more significantly decreased in all the LAB-treated groups than in the positive control. Thus, the administration of mixed $\mathrm{LAB}$ is considered effective in alleviating the symptoms of $\mathrm{AD}$ in an animal model.

Although it cannot be concluded that the results of this experiment, which measured the level of cytokine related with Th1 and Th2, definitely indicate the alleviation of the symptoms of $\mathrm{AD}$, it was demonstrated in this study that the administration of LAB alleviated the symptoms of AD by decreasing the level of IL-4 (Th2 family) and increasing the level of IL-12 and IFN-gamma (Th1 family of cytokines). As such, it was found that the administration of mixed $L A B$ is more effective than that of a single $L A B$ strain in that the level of cytokines in the mixed-LAB-treated became closer to the normal level than that in the group treated with a single LAB strain did. Various stimulants cause keratinocytes to secrete various cytokines, such as IL-4, TNF-alpha, and IFN-gamma, and keratinocytes are influenced by various cytokines via the TGF-beta receptors (Maeda et al., 2001).

Therefore, it was demonstrated that the administration of LAB can alleviate the symptoms of AD by examining the levels of expression of IL-4 and IL-5 in dermal cells due to DNCB in each treatment group. The levels of expression of IL-4 and IL-5 were found to have decreased in all the LAB-treated groups, although the difference between the expression levels in the groups treated with a single LAB strain and in those treated with mixed-LAB was not quantifiable. This result is believed to directly confirm the result observed in the serum as it occurred in the skin in which AD was induced. The beneficial efficacy of LAB is well documented in various literatures, and the role of such bacteria in relation with the immune system was recently reported (Choi et al., 2010). In this study, the improvement effect of LAB on an atopic disease was proven. Therefore, if the four kinds of LAB combinations that were used in this study will be applied to daily products, it is expected that daily products will play an important role in improving the atopic symptoms in atopic patients, and in helping restore such patients' original strength.

\section{Acknowledgement}

This study was partly supported by a grant (No. 10026108) from Ministry of Knowledge Economy of the Republic of Korea. 


\section{References}

1. Aversa, G., Punnonen, J., Cocks, B. G., de Waal Malefyt, R., Vega, F., Jr., Zurawski, S. M., Zurawski, G., and de Vries, J. E. (1993) An interleukin 4 (IL-4) mutant protein inhibits both IL-4 or IL-13-induced human immunoglobulin G4 (IgG4) and IgE synthesis and B cell proliferation: support for a common component shared by IL-4 and IL-13 receptors. $J$. Exp. Med. 178, 2213-2218.

2. Brouwer, M. L., Wolt-Plompen, S. A., Dubois, A. E., van der Heide, S., Jansen, D. F., Hoijer, M. A., Kauffman, H. F., and Duiverman, E. J. (2006) No effects of probiotics on atopic dermatitis in infancy: a randomized placebo-controlled trial. Clin. Exp. Allergy 36, 899-906.

3. Choi, K. O., Nguyen, H. H., and Kwak, H. S. (2010) The role of the immune system in the use of probiotic lactic acid bacteria in preventing and treating allergic diseases. Korean $J$. Food Sci. Ani. Resour. 30, 1-12.

4. Ferrick, D. A., Schrenzel, M. D., Mulvania, T., Hsieh, B., Ferlin, W. G., and Lepper, H. (1995) Differential production of interferon-gamma and interleukin-4 in response to Th1and Th2-stimulating pathogens by gamma delta $\mathrm{T}$ cells in vivo. Nature 373, 255-257.

5. Folster-Holst, R., Muller, F., Schnopp, N., Abeck, D., Kreiselmaier, I., Lenz, T., von Ruden, U., Schrezenmeir, J., Christophers, E., and Weichenthal, M. (2006) Prospective, randomized controlled trial on Lactobacillus rhamnosus in infants with moderate to severe atopic dermatitis. Br. J. Dermatol. 155, 1256-1261.

6. Gunther, C., Bello-Fernandez, C., Kopp, T., Kund, J., Carballido-Perrig, N., Hinteregger, S., Fassl, S., Schwarzler, C., Lametschwandtner, G., Stingl, G., Biedermann, T., and Carballido, J. M. (2005) CCL18 is expressed in atopic dermatitis and mediates skin homing of human memory $\mathrm{T}$ cells. $J$. Immunol. 174, 1723-1728.

7. Hiroi, J., Sengoku, T., Morita, K., Kishi, S., Sato, S., Ogawa, T., Tsudzuki, M., Matsuda, H., Wada, A., and Esaki, K., (1998) Effect of tacrolimus hydrate (FK506) ointment on spontaneous dermatitis in NC/Nga mice. Jpn. J. Pharmacol. 76, 175-183.

8. Homey, B., Steinhoff, M., Ruzicka, T., and Leung, D. Y. (2006) Cytokines and chemokines orchestrate atopic skin inflammation. J. Allergy Clin. Immunol. 118, 178-189.

9. Kalliomaki, M., Salminen, S., Arvilommi, H., Kero, P., Koskinen, P., and Isolauri, E. (2001) Probiotics in primary prevention of atopic disease: a randomised placebo-controlled trial. Lancet 357, 1076-1079.

10. Kay, A. B., Ying, S., Varney, V., Gaga, M., Durham, S. R., Moqbel, R., Wardlaw, A. J., and Hamid, Q. (1991) Messenger RNA expression of the cytokine gene cluster, interleukin 3 (IL-3), IL-4, IL-5, and granulocyte/macrophage colonystimulating factor, in allergen-induced late-phase cutaneous reactions in atopic subjects. J. Exp. Med. 173, 775-778.

11. Ker, J. and Hartert, T. V. (2009) The atopic march: what's the evidence? Ann. Allergy Asthma. Immunol. 103, 282-289.

12. Kim, J. Y., Kwon, J. H., Ahn, S. H., Lee, S. I., Han, Y. S.,
Choi, Y. O., Lee, S. Y., Ahn, K. M., and Ji, G. E. (2010) Effect of probiotic mix (Bifidobacterium bifidum, Bifidobacterium lactis, Lactobacillus acidophilus) in the primary prevention of eczema: a double-blind, randomized, placebocontrolled trial. Pediatr Allergy Immunol. 21, e386-393.

13. Lester, M. R., Hofer, M. F., Gately, M., Trumble, A., and Leung, D. Y. (1995) Down-regulating effects of IL-4 and IL10 on the IFN-gamma response in atopic dermatitis. $J$. Immunol. 154, 6174-6181.

14. Leung, D.Y. and Bieber, T. (2003) Atopic dermatitis. Lancet 361, 151-160.

15. Maeda, S. and Yanagihara, Y. (2001) Inflammatory cytokines (IL-4, IL-5 and IL-13). Nippon Rinsho 59, 1894-1899.

16. Mancini, A. J., Kaulback K., and Chamlin S. L. (2008) The socioeconomic impact of atopic dermatitis in the United States: a systematic review. Pediatr. Dermatol. 25, 1-6.

17. Matsuda, H., Watanabe, N., Geba, G. P., Sperl, J., Tsudzuki, M., Hiroi, J., Matsumoto, M., Ushio, H., Saito, S., Askenase, P. W., and Ra, C. (1997) Development of atopic dermatitislike skin lesion with IgE hyperproduction in NC/Nga mice. Int. Immunol. 9, 461-466.

18. Ohmen, J. D., Hanifin, J. M., Nickoloff, B. J., Rea, T. H., Wyzykowski, R., Kim, J., Jullien, D., McHugh, T., Nassif, A. S., and Chan, S. C. (1995) Overexpression of IL-10 in atopic dermatitis. Contrasting cytokine patterns with delayed-type hypersensitivity reactions. J. Immunol. 154, 1956-1963.

19. Pivarcsi, A., Gombert, M., Dieu-Nosjean, M. C., Lauerma, A., Kubitza, R., Meller, S., Rieker, J., Muller, A., Da Cunha, L., Haahtela, A., Sonkoly, E., Fridman, W. H., Alenius, H., Kemeny, L., Ruzicka, T., Zlotnik, A., and Homey, B. (2004) CC chemokine ligand 18, an atopic dermatitis-associated and dendritic cell-derived chemokine, is regulated by staphylococcal products and allergen exposure. J. Immunol. 173, 5810-5817.

20. Rosenfeldt, V., Benfeldt, E., Nielsen, S. D., Michaelsen, K. F., Jeppesen, D. L., Valerius, N. H., and Paerregaard A. (2003) Effect of probiotic Lactobacillus strains in children with atopic dermatitis. J. Allergy Clin. Immunol. 111, 389395.

21. Rousset, F., Robert, J., Andary, M., Bonnin, J. P., Souillet, G., Chretien, I., Briere, F., Pene, J., and de Vries, J. E. (1991) Shifts in interleukin-4 and interferon-gamma production by $\mathrm{T}$ cells of patients with elevated serum IgE levels and the modulatory effects of these lymphokines on spontaneous IgE synthesis. J. Allergy Clin. Immunol. 87, 58-69.

22. Suto, H., Matsuda, H., Mitsuishi, K., Hira, K., Uchida, T., Unno, T., Ogawa, H., and Ra, C. (1999) NC/Nga mice: a mouse model for atopic dermatitis. Int. Arch. Allergy Immunol. 120 Suppl 1, 70-75.

23. Taylor, A. L., Dunstan, J. A., and Prescott, S. L. (2007) Probiotic supplementation for the first 6 months of life fails to reduce the risk of atopic dermatitis and increases the risk of allergen sensitization in high-risk children: a randomized controlled trial. J. Allergy Clin. Immunol. 119, 184-191.

24. Tazawa, T., Sugiura, H., Sugiura, Y., and Uehara, M. (2004) Relative importance of IL-4 and IL-13 in lesional skin of 
atopic dermatitis. Arch. Dermatol. Res. 295, 459-464.

25. van der Kleij, H. P., Kraneveld, A. D., van Houwelingen A. H., Kool, M., Weitenberg, A. C., Redegeld, F. A., and Nijkamp, F. P. (2004) Murine model for non-IgE-mediated asthma. Inflammation 28, 115-125.

26. Vestergaard, C., Yoneyama, H., and Matsushima, K. (2000) The NC/Nga mouse: a model for atopic dermatitis. Mol. Med. Today 6, 209-210.

27. Viljanen, M., Pohjavuori, E., Haahtela, T., Korpela, R., Kuitunen, M., Sarnesto, A., Vaarala, O., and Savilahti, E. (2005)
Induction of inflammation as a possible mechanism of probiotic effect in atopic eczema-dermatitis syndrome. J. Allergy Clin. Immunol. 115, 1254-1259.

28. Wakabayashi, H., Nariai C., Takemura F., Nakao W., and Fujiwara, D. (2008) Dietary supplementation with lactic acid bacteria attenuates the development of atopic-dermatitis-like skin lesions in NC/Nga mice in a strain-dependent manner. Int. Arch. Allergy Immunol. 145, 141-151.

(Received 2011.3.10/Revised 1st 2011.6.15, 2nd 2011.6.23/ Accepted 2011.6.27) 